\title{
Stanley Fish (2011). How to Write a Sentence and How to Read One (New York and London: Harper), pp. 165, US \$14.99 (p/b), ISBN 978-0-06-184053-1
}

\author{
Shiva Kumar Srinivasan \\ Behavioral Sciences, International Institute of Planning and Management, Chennai, India
}

\begin{abstract}
This review attempts to analyze why pragmatists like Stanley Fish are interested in the structure of sentences when the traditional assumption is that not only do pragmatists think but also go on to argue that all philosophers think mainly in terms of conceptual vocabularies rather than in propositions. It also attempts to understand why Fish uses the language of English composition studies rather than that of deconstruction as is usually the case in such instances. Fish's invocation of Noam Chomsky's theories of child language acquisition is also invoked to differentiate between the ability to analyze sentences and the ability to generate sentences in natural languages. The review concludes by stating that the main challenge in courses on reading and writing is to find a solution to the problem of generativity rather than stop with the analysis of sentences per se.
\end{abstract}

Keywords: Competence, Generativity, Performance, Proposition, Sentence

\section{Introduction}

There is a wide-spread assumption amongst rationalist philosophers that pragmatists like Stanley Fish think only or mainly in terms of conceptual vocabularies rather than in terms of logical propositions like they do. Getting pragmatists to think in logical propositions would - in their estimation - be a difficult task given that propositional thinking is related to theories of truth, which the pragmatists problematize in terms of 'what works or doesn't work' rather than in terms of propositional content and truth conditions. Rationalists also like the idea of implicating pragmatists in the philosophical 'problem of translation' by invoking the following argument: Pragmatists think only or mainly in vocabularies; this is a problematic practice given that the semantic 'value' of a term within a conceptual vocabulary is specific to a language; so, sooner or later, there will be a problem of translation. This is because the conceptual space of an episteme is analogous to that of a natural language. Words, concepts, and most lexical items don't translate well since not only do they have different 'connotations' in different languages as students of literature know, but also different 'semantic values' (given their differential placement within the structure of natural languages) as Saussurean linguists are fond of pointing out. Ergo, pragmatists should not be interested in sentences in the first place, or if they are, they should explain whether they are back-pedaling their way to a concealed or minimalist notion of propositional structure. These arguments are also compounded by the fact that syntactic approaches to language (especially that of the linguist Noam Chomsky) are historically within the Cartesian tradition of rationalism given the Chomskyian critique of B.F. Skinner.

\section{Sentences And Propositions}

How are we then to make sense of Fish's interest in sentences? Why does he define the 'sentence' rather than a 'concept' as the basic unit of cognition, comprehension, and literary emulation in this book? Why furthermore does Fish pitch this book rather modestly within composition studies? These then are the sort of questions that will seize the mind of his European readers. Most literary theorists on the continent might have preferred a book titled How to Construct a Proposition and How to Deconstruct One. They will also wonder why a critic of Fish's stature is content to work merely with the technical vocabulary of English composition studies as symbolized by the terms 'write' and 'read' rather than with the more philosophically glamorous equivalents: 'construct' and 'deconstruct'. Not only will they do this, I also have good reason to believe that they will drag in a few mediaeval schoolmen like Peter Abelard and Thomas Aquinas into their arguments for good measure, and then wonder why Fish doesn't appreciate their gesture when they are taking his book so seriously by constructing a philosophical genealogy for it. They will also want to know why an erudite literary theorist like Fish is so parsimonious with his philosophical references. The only philosophers that Fish refers to in this book are J. L. Austin and Noam Chomsky, and that too in passing. And what is even more vexing from a European point of view is the fact that Fish takes empirical research in English composition studies too seriously. The most telling instance of this is when Fish argues that teaching formal grammar has no beneficial effects on how students write, and that it may even be counter-productive to teach formal grammar in some 
instances. This style of writing then is a form of theoretical minimalism that is rooted in the American tradition of taking composition studies seriously given that American colleges make a huge fuss about the learning requirements of freshmen. It is important for readers outside the United States to come to terms with this turn of thought in Fish's career if they want to make sense of this deceptively simple book. Here is somebody who actually wants to teach his students to write, and not merely demonstrate how learned he is in the traditions of writing, or merely locate a point of convergence between the syntactic, the semantic, and the logical in the grammatological tradition of the French philosopher, Jacques Derrida.

\section{Generation Of Sentences}

The test case for Fish's analysis of sentences is whether an exposure to syntactic form per se will lead to the actual generation of sentences by students quickly enough in a course in English composition. This is not unlike the relationship between 'competence and performance' in the Chomskyan model of cognition. The main difference though is that Chomsky locates competence as an in-built cognitive faculty in the human mind; hence the attempt to create a Cartesian tradition of rationalism for it. Generativity, in the Chomskyan model (i.e. the ability to generate an unlimited number of sentences in a young child) however requires some empirical exposure to a community of language users irrespective of which language we are discussing. What is in-built into the child's mind is not any particular language, but the grammatical wherewithal as cognitive potential. The realization of any particular grammar is however empirically instantiated when it is activated at a specific point in early childhood. What is really at stake for both theory and practice is the problem of generativity in the context of child language acquisition. The child's linguistic performance has to be understood by invoking a notion of what the determining conditions of generativity might be for so much linguistic success at such a tender age. There is a continual sense of wonder in Chomsky at the fact that the young child often produces sentences that have never been produced before in historical time, albeit with grammatical forms that repeat themselves as patterns that can be formalized within comparative grammatical theory.

\section{Generativity In Composition}

Fish's foray in compositional studies then is equivalent to asking an analogous question: What leads to generativity in courses in English composition? The main difference however between the tenor of Chomsky's question and Fish's question is this. The acquisition of language in childhood requires exposure to informal, everyday contexts in which language is used. It does not require a child to do a course on the formal grammar of any language since the ability to generate sentences with the fluency of a native speaker in early childhood is cognitively of a different order from being able to analyze the sentences that are actually generated either by the child himself or by a linguist who uses these sentences as empirical data to analyze sentences. Likewise, doing formal courses succeeds mainly in sharpening the analytic faculty without necessarily leading to the production of new sentences. This is the problem that is routinely encountered in courses in English composition, creative writing, and technical writing: it is the bedrock on which these courses invariably fail. The additional variable that Fish has to account for, and which is not so crucial in the Chomskysan model, is linguistic style. The typology of sentences that Fish analyzes in this book is related to the problem of linguistic style and cognitive style, and whether the process of literary emulation should be attempted while teaching English composition for college freshmen. And, if yes, what might the modalities of such emulation be? One of the main tasks that Fish sets for himself is to identify a representative collection of sentences with which his students can work in the classroom. This incidentally is a technique that American faculty in literary studies are quite fond of. The analysis of the chosen sentence or sentences then becomes a synecdoche for the analysis of the literary text as a whole.This technique is relevant to both teaching English composition for freshmen and in identifying the linguistic mechanisms that constitute the stuff of literary analysis. This technique, I think, can also be used in courses in legal communication. The word 'sentence', needless to say, marks the point of convergence between Fish's interest in English composition and legal communication. Jurists are preoccupied with 'sentencing guidelines', while English faculty are content to merely write guidelines for generating sentences in the context of English composition. The resonance of the word 'sentence' however should not be lost in close reading Fish's work in either legal studies or English studies.

\section{Teaching English Composition}

Or, to put it simply, the European reader must come to terms with the fact that Fish is mainly (or, in their terms,only) pitching for readers of College English with a hint of its usefulness for legal communication, but does not invoke an alternate philosophy like Jacques Derrida might at this point of the argument. To situate this book as an attempt to solve the problems of those who read journals like College English while teaching courses in English composition in American academia will - for those who truly understand the spirit of Fish's academic work - not necessarily be a huge putdown, but could even be construed as a compliment. The advice that I myself heard Fish give his students from as early as the 1990s in the United States was that teaching 
courses in English composition is not a form of failure; it is in fact an interesting challenge for those with a pragmatist orientation to teaching. However, in order to make a success of such a course in English composition, the instructor must come to terms with questions that are analogous to the Chomskyan question of generativity without making the rationalist decision to spend a life time asking that question repeatedly. Instead, the pragmatist, equipped with a rather modest array of theoretical insights will proceed through a process of trial-and-error to apply the question of generativity, and the analytic distinction between 'generating' and 'analyzing' sentences, to work in the composition classroom. There are also a few additional points that are worth raising here before closing this review: To what extent can we think through the Chomskyan analogue in Fish? For instance, Chomsky's work relies on the 'critical period hypothesis' - this notion does not play a role in Fish's argument at all. The language module in a child's mind can be successfully activated only during a critical period in early childhood. If a child is deprived of sufficient linguistic interaction like the so-called 'wolf-children', they may not be able to acquire spoken language skills later on in life. Is there a critical period that will constitute the determining conditions for literary emulation in English composition? So, for instance, is it already a bit too late to teach English composition in college for freshmen? Will Fish's approaches to literary emulation through writing sentences be more applicable in high schools or junior schools? What do we actually know about the ability of children to write sentences with some intuition of literary style? How if at all can we correlate these abilities in school and college? Can these correlations serve as effective predictors of later academic performance on the part of the students concerned? It might have been a good idea if Fish had included some literary anecdotes of those who actually learnt to write using the model of 'literary emulation' like R. L. Stevenson and Mark Twain. These are examples that come readily to mind but there are many more like Stevenson and Twain in the history of literature - especially classical literature, where analyzing sentences from the Greek and Latin was synonymous with the attempt to learn these languages on the part of students studying the ancient classics.

\section{Conclusion}

These then are but a sample of the tremendous range of questions; which, if answered adequately by both theorists and practitioners of English composition, will have enormous pedagogical applications for how students are taught to read and write in schools and colleges in the years to come. I think that in addition to the hypothetical College English audience that I have previously mentioned, this book will be of help in departments of education since Fish's attempt to correlate reading and writing as cognitive practices is relevant to not only those working on theories of cognition and theories of learning, but also to the development of curricula in departments of English language, literature, cognitive linguistics, and, above all, composition studies. 